\title{
UJI KEAUSAN BESI COR BERLAPIS HARDCHROME MENGGUNAKAN TRIBOTESTER PIN-ON-DISC
}

\author{
Wahyu Anuwar Witoyo, Imam Syafa'at*, Darmanto \\ Jurusan Teknik Mesin Fakultas Teknik Universitas Wahid Hasyim Semarang \\ Jln. Menoreh Tengah X/22 Sampangan, Semarang, Indonesia \\ *Email: imamsyafaat@unwahas.ac.id
}

\begin{abstract}
Abstrak
Besi cor memiliki rasio kekuatan terhadap massa yang paling tinggi. sehingga banyak digunakan sebagai bahan komponen mesin, misalkan gesekan yang terjadi pada ring piston dengan bore cylinder yang merupakan komponen drive train dari sistem motor bakar. Akibat dari kerja komponen tersebut maka akan timbul adanya keausan permukaan komponen. Tujuan penelitian ini adalah untuk mengetahui fenomena keausan besi cor dengan perlakuan permukaan electroplating hardchrome dengan menggunakan metode pengujian pin on disk tribometer, yang dilakukan dengan pelumasan SAE 10w-30 pada pembebanan $10 \mathrm{~N}$ dan $20 \mathrm{~N}$ dengan kecepatan putaran 60rpm dan jarak 200m, 300m, 400m, 500m, 600m setiap jarak dilakukan pengukuran keausan pada spesimen pin dan disc. Hasil pengujian keausan pada spesimen yang terbuat dari material besi cor dan dilapisi hardchrome dengan menggunakan pelumas SAE 10W-30 memperoleh kesimpulan bahwa setiap jarak keausan pada disk meningkat, Perhitungan keausan dengan menggunakan metode Archard yang menunjukkan tinggi keausan tertinggi sebesar $0.016729 \mathrm{~mm}$ pada jarak $600 \mathrm{~m}$ di disc A beban $10 \mathrm{~N}$ dan terendah sebesar $0.003035 \mathrm{~mm}$ pada jarak $200 \mathrm{~m}$ di disc B beban 10n. Nilai volume keausan terbesar pada disc B beban $20 \mathrm{~N}$ berkisar $1.1741 \mathrm{~mm}^{3}$ pada jarak $600 \mathrm{~m}$. Serta volume keausan terendah pada disc A sebesar $0.2720 \mathrm{~mm}^{3}$ pada jarak $200 \mathrm{~m}$ dengan jenis keausan yang terjadi adalah keausan abrasi.
\end{abstract}

Kata kunci : besi cor, electroplating hardchrome, kekasaran buatan, keausan abrasi.

\section{PENDAHULUAN}

Sejalan semakin tingginya ilmu pengetahuan dan teknologi yang lebih modern, dalam dunia permesinan untuk memperpanjang umur pemakaian sebuah permesinan ada beberapa hal yang harus diperhatikan, misalnya cara pemakaian, kualitas bahan dan cara perawatannya. Permasalahan yang terjadi setiap komponen mesin adalah adanya gesekan satu sama lain yang terjadi bila komponen-komponen dalam permesinan saling kontak. sehingga menimbulkan adanya keausan permukaan komponen.

Keausan (wear) dianggap sebagai fenomena permasalahan utama dalam sistem tribology dan didefinisikan sebagai hilangnya material dari permukaan yang bersinggungan di dalam gerakan relative yang dikendalikan oleh sifat material (kekerasan, keuletan, sifat termal), lingkungan (jenis pelumas, suhu), kondisi operasional (topografi permukaan, beban, kecepatan) dan geometri dari permukaan yang bersinggungan (Cracaoanu, 2010).

Syafa'at (2008) secara prinsip, pelumasan berfungsi untuk mencegah keausan yang disebabkan oleh gesekan antar benda yang bergerak relative. Fungsi lain dari pelumas adalah untuk mengurangi gesekan, sebagai kompresi seal, meredam noise, sebagai pendingin bagian part, mencegah karat, dapat menjaga part tetap bersih.

(Watson \& Gawne, 1997) telah mempraktikkan teknik pelapisan chrome terhadap besi cor, Bahan penekan identor atau pin berbahan besi dengan panjang $60 \mathrm{~mm}$ serta berdiameter $6,35 \mathrm{~mm}$. Spesimen flat dilapisi chrome dengan nilai ketebalan $10 \mu \mathrm{m}$ dan $60 \mu \mathrm{m}$. Di dalam praktiknya terdapat kegagalan lapisan setelah dilakukan pengujian pin-on-flat.

Nasrudin (2016) Menganalisis keausan cylinder baja st 90 menggunakan Tribotester pin-on-disc dengan variasi pelumas menunjukkan bahwa pada kondisi tanpa 
pelumasan memiliki volume keausan yang paling tinggi, yaitu $0,011 \mathrm{~cm}^{3}$. Pada kondisi pelumasan volume keausan yang terjadi pada pin tidak mengalami perubahan dengan nilai volume keausan yang tertinggi pada SAE 40 sebesar $0,0038 \mathrm{~cm}^{3}$. SAE 90 dengan nilai volume keausan sebesar $0.0038 \mathrm{~cm}^{3}$. Dan SAE 140 dengan nilai keausan volume keausan sebesar $0.0038 \mathrm{~cm}^{3}$,. Semakin tinggi nilai dari viskositas suatu pelumas maka semakin kecil volume keausan yang terjadi pada pin..

Keausan besi cor grafit bulat telah diteliti oleh (Muchammad dkk., 2018) untuk aplikasi Cylinder liner menggunakan tribotester pin on disk. Penelitian ini bertujuan untuk mengetahui volume dan tinggi keausan yang terjadi pada besi cor FCD 50 (79,5 HRB), FCD 50 (82 HRB), dan FCD 60 (86,5 HRB), Analisa perhitungan menggunakan penurunan geometri (Archard, 1953). volume keausan dan tinggi keausan yang paling besar terjadi pada besi cor FCD 50 dengan kekerasan 79,5 HRB.

Sugiharto (2017) menganalisis keausan dengan membandingkan dua buah spesimen yang berbeda. Kedua spesimen tersebut berupa disc FCD 50 dan FCD 60 dengan alur buatan hasil pembubutan knurling DIN 82 melalui pengujian tribometer pin-on-disc tanpa pelumas. Jenis knurling yang dipakai adalah RBL left-hand spiral dengan pitch 0,3 $\mathrm{mm}$. Pin berbentuk bola dengan standar AISI 52100 berdiameter $9,5 \mathrm{~mm}$. Tingkat keausan tertinggi pada disc FCD 50 dengan volume keausan $6,9581 \mathrm{~mm}^{3}$ pada jarak $600 \mathrm{~m}$. Dan nilai keausan terendah pada disc FCD 60 dengan volume $0,8742 \mathrm{~mm}^{3}$ pada jarak $200 \mathrm{~m}$. Dari analisa tersebut disimpulkan nilai kekerasan material berpengaruh terhadap volume keausan, koefisien keausan dan tinggi keausan.

Keausan baja ST.40 menggunakan tribotester pin-on-disc pernah dilakukan oleh (Rohadi dkk., 2013) dengan kondisi pelumas menggunakan SAE 40 dan SAE 140. Pengujian tersebut menunjukkan pin dengan variasi pelumas didapatkan penurunan berat pin yang besar pada pengujian pin dengan variasi tanpa pelumas sebesar 3,74 g. sedangkan penurunan berat pin yang kecil sebesar 0,02 g pada pengujian menggunakan pelumas SAE 140.

Pengerasan permukaan atau melakukan penambahan lapisan permukaan dapat mengurangi nilai keausan dari sebuah material. Perlakuan permukaan merupakan suatu cara untuk merancang permukaan benda padat dengan merubah, dan menambah bahan baru sebagai pelapis, secara umum bersifat sebagai pelindung dan meningkatkan unjuk rupa. Salah satu jenis perlakuan permukaan adalah dengan metode pelapisan listrik yaitu electroplating hardchrome. Electroplating hardchrome adalah jenis penambahan lapisan permukaan yang berbahan dasar kromium. Penambahan lapisan Hardchrome secara umum dilakukan pada alat-alat industri yang bergerak, salah satu aplikasinya adalah camshaft. fungsi dari camshaft adalah sebagai penggerak katup hisap untuk memasukkan bahan bakar dari intake manifold ke saluran port menuju ruang bakar (Priyono dkk., 2019). mekanisme cam dapat dilihat seperti pada gambar 1 .

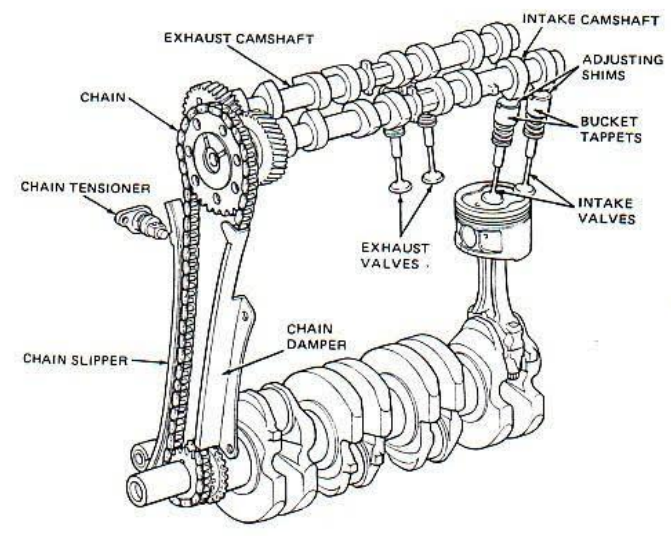

\section{Gambar 1. Mekanisme Camshaft (HPM E-Learning System)}

Tribometer adalah perangkat yang digunakan untuk mengukur gesekan dan keausan antara dua permukaan. Alat Tribometer pin-on-disc adalah alat uji gesek untuk mengetahui keausan pada pin dan disc. Berbagai ukuran dan bentuk pin dapat digunakan, misalnya seperti bentuk bola atau silinder tabung, dan disc berbentuk piringan dengan plat berdiameter tebal berbagai ukuran. Pemakaian alat pin on disc untuk mengetahui keausan berjenis rolling dan sliding. Dari penelitian diatas belum ada 
penelitian lebih lanjut mengenai lapisan hardchrome menggunakan pelumasan. Maka dari itu dalam penelitian ini dilakukan analisa pengujian pin-on-disc untuk mengetahui ketahanan gesek permukaan besi cor berlapis electroplating hardchrome menggunakan pelumas SAE 10W-30 yang dapat mengurangi gesekan antara pin dan disc yang saling bersinggungan.

\section{METODOLOGI}

Metode penelitian yang digunakan adalah dengan cara pengujian keausan besi cor berlapis hardchrome menggunakan alat tribotester pin-on-disc dengan pelumas SAE $10 \mathrm{w}-30$ dan kecepatan putaran disc diatur menggunakan Inverter dengan kecepatan putaran $60 \mathrm{rpm}$ dan beban pada pin $10 \mathrm{~N}$ dan $20 \mathrm{~N}$ dengan menempuh jarak $200 \mathrm{~m}, 300 \mathrm{~m}$, $400 \mathrm{~m}, 500 \mathrm{~m}$, dan $600 \mathrm{~m}$ seperti pada gambar 2 dibawah ini.

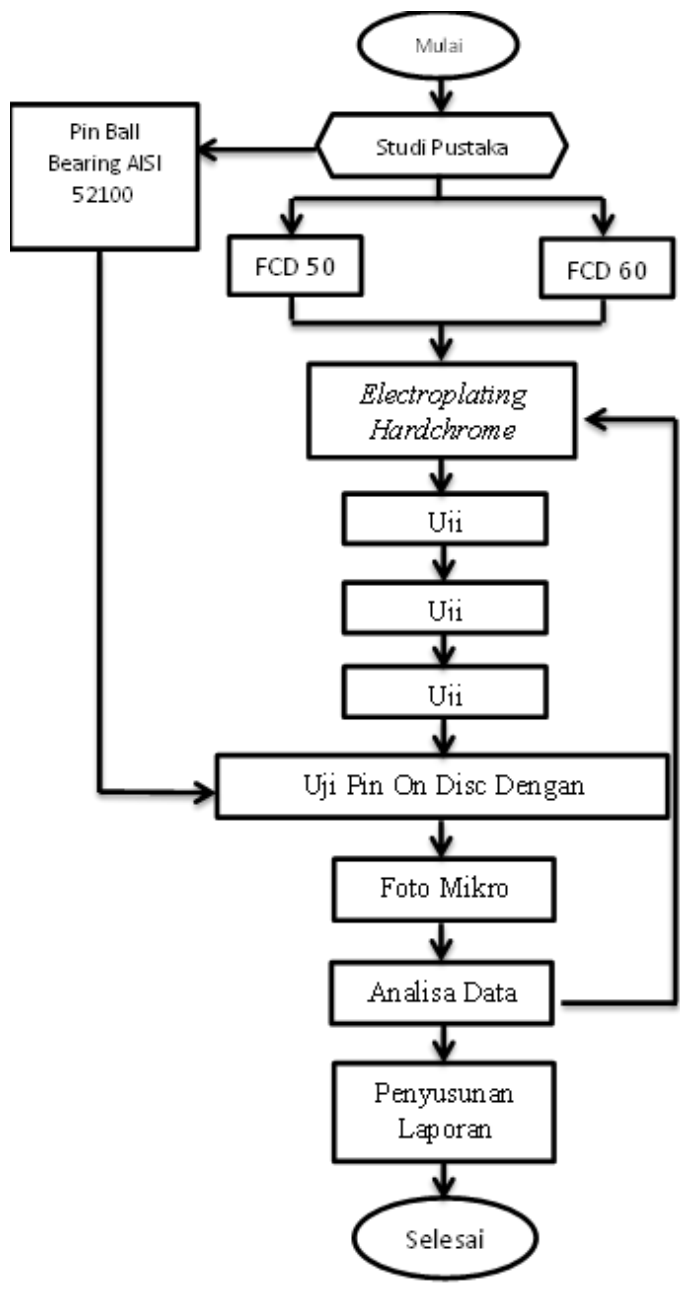

Gambar 2. Alur Penelitian
Bahan yang digunakan untuk eksperimen yakni bahan uji (specimen) berupa dua buah besi cor berbentuk disc $\mathrm{A}$ dan disc $\mathrm{B}$ berdiameter 151,50 mm dan tebal keseluruhan 25,60 mm. Lanhkah selanjutnya adalah proses elektroplating yang terdiri dari pengerjaan awal, proses pelapisan dan pengerjaan akhir pelapisan listrik krom keras. Tahapan selanjutnya pengujian pin-on-disc (POD) dengan pelumas SAE 10w-30 pada disc. Pengujian foto mikro kedua spesimen (disc) setelah proses pelapisan permukaan dan pengujian gesekan, tahap selanjutnya dilakukan foto mikro untuk mengetahui bentuk keausan akibat gesekan pin-on-disc.

\section{HASIL DAN PEMBAHASAN}

Pada pengujian pin-on-disk menggunakan pelumas SAE 10w-30 dengan material besi cor FCD 50 dan FCD 60 menggunakan alat tribotester, didapatkan hasil pengujian seperti pada tabel 1. Permukaan disc A dan disc $\mathrm{B}$ kekasarannya meningkat dari sebelum di hardchrome dan setelah di hardchrome. Nilai peningkatan kekasaran disc B sebesar 26,77\% dan disc A sebesar 20,15\%. Nilai peningkatan kekerasan permukaan disc A sebesar $382 \%$ dan disc B sebesar $208 \%$.

Tabel 1. Data pin dan disc

\begin{tabular}{|c|c|c|c|}
\hline \multirow{2}{*}{ No } & & \multicolumn{2}{|r|}{ Nilai } \\
\hline & & Norma & l Hardchrome \\
\hline 1 & Kekasaran disc A & $\begin{array}{l}0.516 \\
\mu m\end{array}$ & $0.62 \mu m$ \\
\hline 2 & Kekasaran disc B & $\begin{array}{c}0.623 \\
\mu m\end{array}$ & $0.786 \mu m$ \\
\hline 3 & Kekerasan disc A & $\begin{array}{l}79.5 \\
\text { HRB }\end{array}$ & $714.2 \mathrm{HV}$ \\
\hline 4 & Kekerasan disc A & $\begin{array}{c}86.5 \\
\text { HRB }\end{array}$ & $530.6 \mathrm{HV}$ \\
\hline 5 & Beban pengujian & & $\begin{array}{l}10 \mathrm{~N} \\
20 \mathrm{~N}\end{array}$ \\
\hline 6 & $\begin{array}{c}\text { Ketebalan lapisan } \\
\text { disc A }\end{array}$ & & $9.3 \mu \mathrm{m}$ \\
\hline 7 & $\begin{array}{c}\text { Ketebalan lapisan } \\
\text { disc } \mathrm{B}\end{array}$ & & $11.5 \mu \mathrm{m}$ \\
\hline
\end{tabular}

Foto mikro hasil eksperimen disc A dan disc B hanya pada jarak 200m dengan beban $10 \mathrm{~N}$ dan $20 \mathrm{~N}$ yang telah diukur lebar kontak ausnya dengan menggunakan mikroskop metalografi adalah sesuai dengan gambar 3 . 


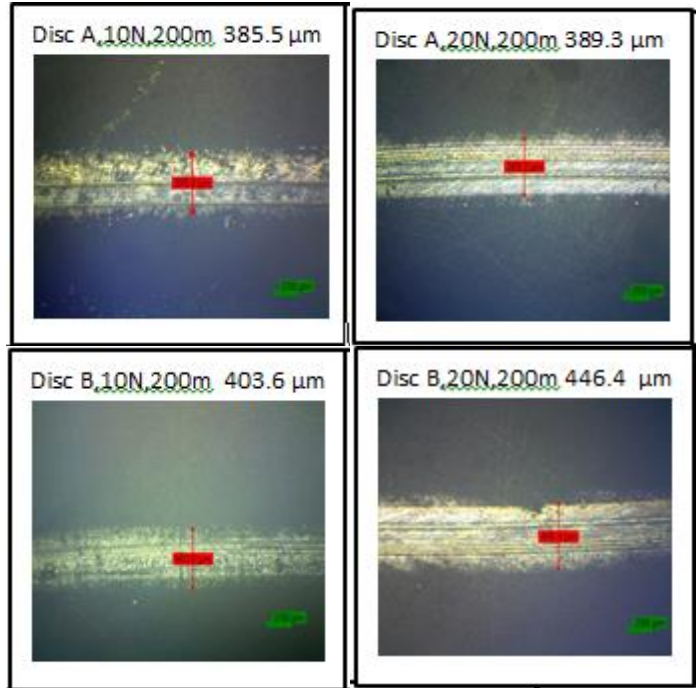

\section{Gambar 3. Foto mikro disc}

Berdasarkan gambar 3 dapat diambil keterangan semakin besar pembebanan pada pin dan bertambahnya jarak maka Semakin besar nilai lebar keausannya. Lebar Keausan Permukaan Disc dapat dilihat pada gambar 2 Waktu yang ditempuh dengan membandingkan jarak tempuh terhadap kecepatan disc diatas sistem tribometer.

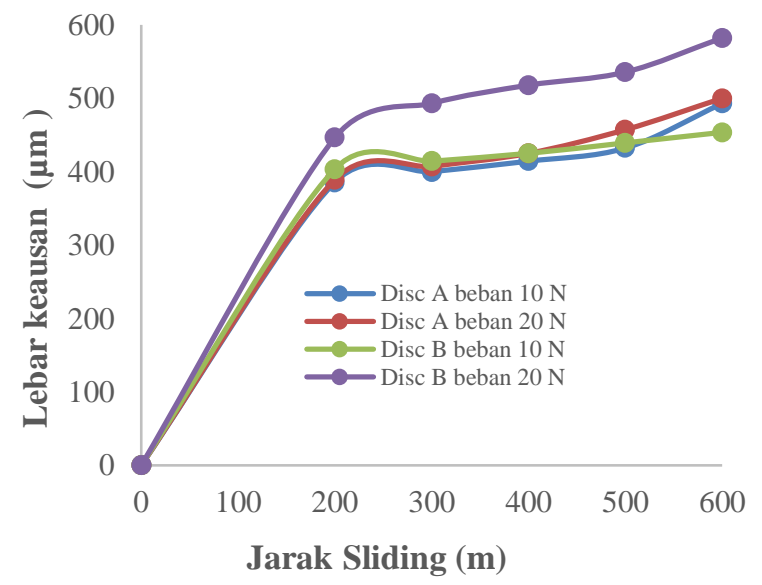

\section{Gambar 4. Grafik lebar keausan disc A dan $\operatorname{disc} \mathrm{B}$}

Hasil perbandingan lebar kontak keausan disc dapat dilihat pada gambar 4 perbandingan lebar kontak keausan disc tertinggi pada disc B dengan jarak $600 \mathrm{~m}$ sebesar $582.2 \mu \mathrm{m}$ dan terendah pada disc A dengan jarak $200 \mathrm{~m}$ sebesar $385.8 \mu \mathrm{m}$. Nilai volume keausan yang dialami disc A dan B ditiap-tiap jarak dapat dilihat pada gambar 5 .

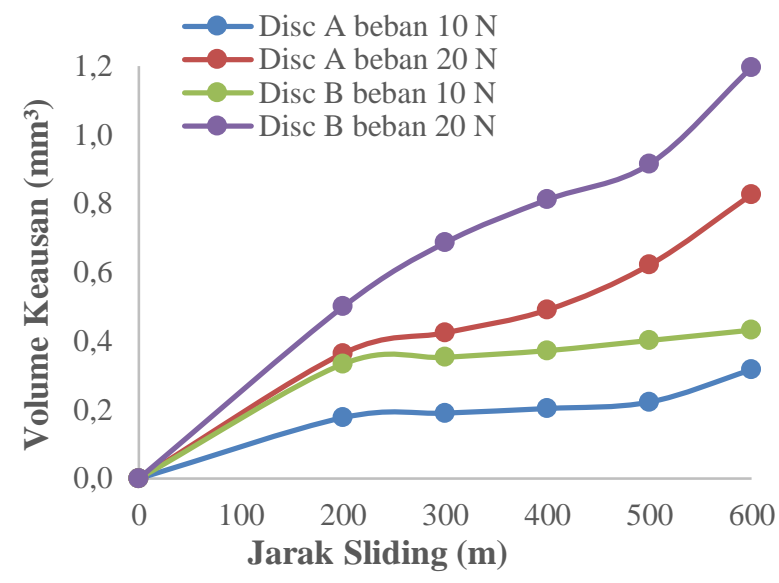

\section{Gambar 5. Grafik perbandingan volume keausan disc A dan disc $\mathrm{B}$}

Dari gambar 5 volume keausan disc dapat dilihat nilai volume keausan tertinggi pada disc B beban 20N dengan jarak $600 \mathrm{~m}$ sebesar $1.1958 \mathrm{~mm}^{3}$ dan terendah pada disc A beban 20N dengan jarak $200 \mathrm{~m}$ sebesar $0.1771 \mathrm{~mm}^{3}$. Kedalaman keausan dari pengujian kontak sliding antara pin dan kedua disc adalah terlihat pada gambar 6 .

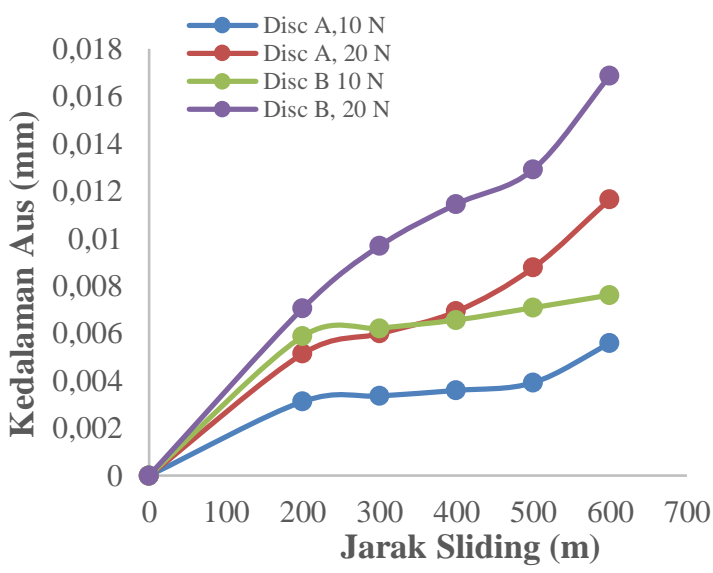

\section{Gambar 6. Grafik perbandingan tinggi keausan disc A dan disc B}

Dari gambar 6 Nilai tinggi keausan tertinggi pada disc B dengan jarak $600 \mathrm{~m}$ sebesar $0.016879019 \mathrm{~mm}$ dan terendah pada disc A dengan jarak $200 \mathrm{~m}$ sebesar $0.00312336 \mathrm{~mm}$. Pengaruh perubahan beban 
pada nilai koefisien aus dapat dilihat pada gambar 7.

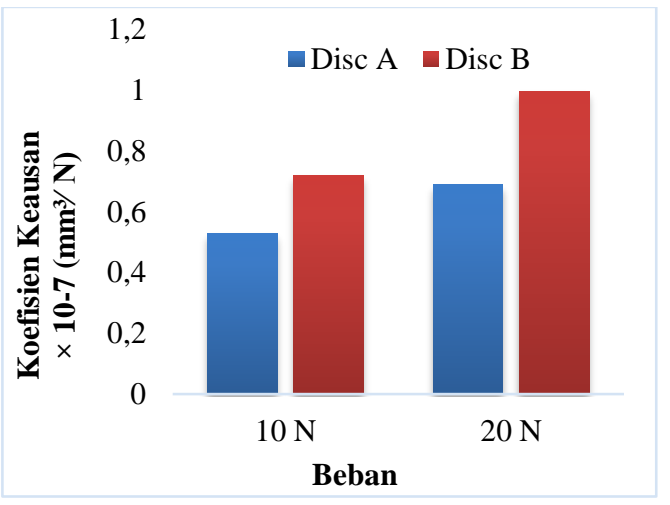

\section{Gambar 7. Koefisien Aus}

Pada gambar 7 diatas dapat dilihat bahwa nilai koefisien aus pada disc A pembebanan $10 \mathrm{~N}$ jarak $600 \mathrm{~m}$ sebesar $5,25 \mathrm{x}$ $10^{-8} \mathrm{~mm}^{2} / \mathrm{N}$.mm. lebih kecil dari disc A pembebanan $20 \mathrm{~N}$ jarak $600 \mathrm{~m}$ sebesar $6,88 \mathrm{x}$ $10^{-8} \mathrm{~mm}^{2} / \mathrm{N} . \mathrm{mm}$. Sedangkan pada disc B pembebanan $10 \mathrm{~N}$ jarak $600 \mathrm{~m}$ sebesar $7,19 \mathrm{x}$ $10^{-8} \mathrm{~mm}^{2} / \mathrm{N}$.mm. lebih kecil dari disc B pembebanan $20 \mathrm{~N}$ jarak $600 \mathrm{~m}$ sebesar $9,96 \mathrm{x}$ $10^{-8} \mathrm{~mm}^{2} / \mathrm{N}$.mm. Hal ini sesuai dengan teori bahwa semakin besar pembebanan maka nilai koefesien gesek akan semakin besar.

\subsection{Hasil Pengujian Pin Pada Alat Tribtester Pin-On-Disc}

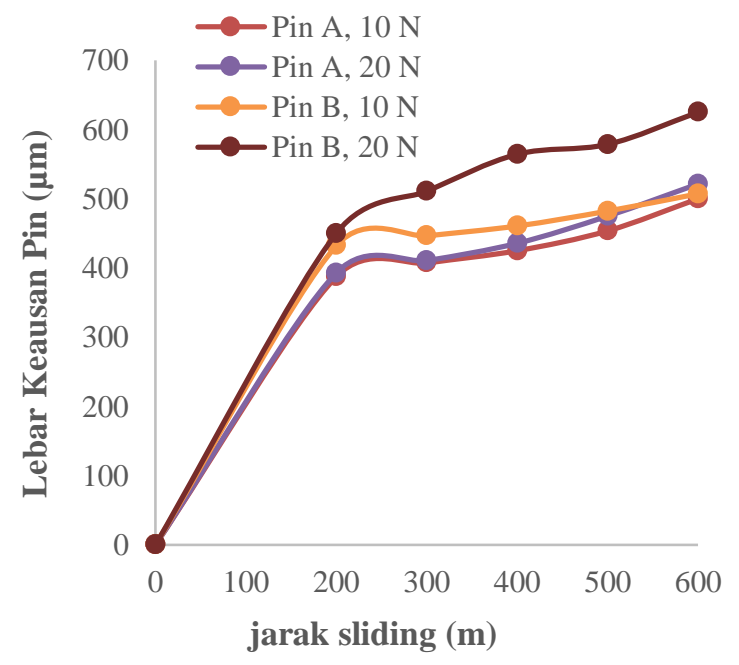

Gambar 8. Grafik lebar keausan pin
Dari grafik gambar 8 diatas dapat dilihat Lebar keausan pin terbesar terjadi pada disc B dengan jarak $600 \mathrm{~m}$ beban $20 \mathrm{~N}$ sebesar $0,625 \mathrm{~mm}$. Sedangkan nilai keausan terkecil pada pin terhadap disc A jarak $200 \mathrm{~m}$ beban $10 \mathrm{~N}$ dengan lebar kontak aus sebesar 0,3874 $\mathrm{mm}$. Nilai keausan kedua pin meningkat seiring bertambahnya jarak. Sedangkan pada pin terhadap kontak disc B rata-rata nilai kontak aus lebih tinggi dari kontak aus pin terhadap disc A. Besarnya nilai keausan pin $\mathrm{B}$ terhadap disc $\mathrm{B}$, karena permukaannya yang sangat kasar. Sehingga kehilangan materi yang dialami semakin banyak.

\section{PENUTUP \\ Kesimpulan}

Kesimpulan yang dapat diambil dari penelitian ini adalah sebagai berikut :

Karakter permukaan disc A dan disc B kekasarannya meningkat dari sebelum di hardchrome dan setelah di hardchrome. Nilai peningkatan kekasaran tertinggi pada disc $\mathrm{B}$ sebesar $26,77 \%$ dan terendah pada disc A sebesar $20,15 \%$. Nilai peningkatan kekerasan permukaan disc A sebesar $382 \%$ dan disc B sebesar 208\%. Peningkatan nilai kekasaran permukaan dan kekerasan bahan, menjadikan nilai tinggi keausan tertinggi pada disc $\mathrm{B}$ dengan jarak $600 \mathrm{~m}$ beban $20 \mathrm{~N}$ sebesar $0.0168790 \mathrm{~mm}$ dan terendah pada disc A dengan jarak $200 \mathrm{~m}$ beban $10 \mathrm{~N}$ sebesar $0.0031233 \mathrm{~mm}$. Dan volume keausan terbanyak pada disc B dengan jarak $600 \mathrm{~m}$ beban $20 \mathrm{~N}$ sebesar $1.1958 \mathrm{~mm}^{3}$. Serta volume keausan terendah pada disc A dengan jarak $200 \mathrm{~m}$ beban $10 \mathrm{~N}$ sebesar $0.1771 \mathrm{~mm}^{3}$. Jenis keausan yang terjadi adalah keausan two body abrasion, sehingga secara analitik nilai keausan meningkat seiring bertambahnya jarak dan waktu.

\section{DAFTAR PUSTAKA}

Archard, J. F. (1953). Contact and rubbing of flat surfaces. Journal of applied physics. https://doi.org/10.1063/1.1721448

Cracaoanu, I. (2010). Effect of macroscopic wear on friction in lubricated concentrated contacts. research.utwente.nl. https://research.utwente.nl/en/publicatio 
ns/effect-of-macroscopic-wear-on-

friction-in-lubricated-concentrated-2

Muchammad, Syafa'at, I., Hilmy, F.,

Tauviqirrahman, M., \& Jamari. (2018).

Wear analysis of spherical graphite cast

iron using pin-on disc tribotester.

Journal of Physical Science, 29, 15-26.

https://doi.org/10.21315/jps2018.29.s2.2

Priyono, S., Syafa'at, I., \& Purwanto, H.

(2019). Analisa Keausan Pin-on-Disc

Besi Cor dengan Kekasaran Permukaan

Buatan dan Electroplating Hardchrome.

Majalah iImiah Momentum, 9(1), 148-

162.

http://jurnal.globalhealthsciencegroup.co

m/index.php/JPPP/article/download/83/6

5\%0Ahttp://www.embase.com/search/re

sults? subaction $=$ viewrecord $\&$ from $=$ expo

rt\&id=L603546864\%5Cnhttp://dx.doi.or

g/10.1155/2015/420723\%0Ahttp://link.s

pringer.com/10.1007/978-3-319-76

Rohadi, A., Darmanto, D., \& ... (2013).

Analisis Keausan Baja St. 40

Menggunakan Tribotester Pin-On-Disc

Dengan Variasi Kondisi Pelumas. Jurnal

Ilmiah

https://publikasiilmiah.unwahas.ac.id/ind

ex.php/MOMENTUM/article/view/926

Watson, A., \& Gawne, D. T. (1997).

Chromium Electrolytes. In Advances in

Surface .... Royal Society of Chemistry. 